RUNNING HEAD: Self- versus Other-Knowledge of Trustworthiness

\title{
An investigation of the impact of young children's self-knowledge of trustworthiness on school adjustment: A test of the Realistic Self-Knowledge and Positive Illusion models
}

Lucy R. Betts,

Nottingham Trent University, UK
Ken J. Rotenberg, \& Mark Trueman

Keele University, UK

Lucy R. Betts, Division of Psychology, Nottingham Trent University, Ken J. Rotenberg and Mark Trueman, School of Psychology, Keele University.

This research was supported, in part, by a grant from the Russell Sage Foundation awarded to the second author. The researchers would like to thank Sarah Rennison for her assistance in data collection. Also, thanks are extended to the school staff and children at the schools that participated in the research including Elworth Hall Primary School, Wheelock Primary School, Wistaston Westfield Infant School and Wybunbury Delves C. E. (Aided) Primary School. Portions of this paper were presented at the British Psychological Society Developmental section annual conference, September 2005. Also, portions of the research served in partial fulfilment of a Ph.D. from Keele University for the first author.

Correspondence should be addressed to: Lucy R Betts, Division of Psychology, Nottingham Trent University, Nottingham, NG1 4BU. Email lucy.betts@ntu.ac.uk Ph +44 (0) $1158485558 \mathrm{Fax}+44(0) 1158486829$. 


\begin{abstract}
The study aimed to examine the relationship between self-knowledge of trustworthiness and young children's school adjustment. One hundred and seventy-three (84 male and 89 female) children from school years 1 and 2 in the United Kingdom (mean age 6 years 2 months) were tested twice over one-year. Children's trustworthiness was assessed using: (a) self-report at Time 1 and Time 2, (b) peers' reports at Time 1 and Time 2, and (c) teacherreports at Time 2. School adjustment was assessed by child-rated school-liking and the ShortForm Teacher Rating Scale of School Adjustment. Longitudinal quadratic relationships were found between school adjustment and children's self-knowledge, using peer-reported trustworthiness as a reference: more accurate self-knowledge of trustworthiness predicted increases in school adjustment. Comparable concurrent quadratic relationships were found between teacher-rated school adjustment and children's self-knowledge, using teacherreported trustworthiness as a reference, at Time 2. The findings support the conclusion that young children's psychosocial adjustment is best accounted for by the Realistic SelfKnowledge Model (Colvin \& Block, 1994).
\end{abstract}

Key words: trustworthiness, early childhood, school adjustment, self-knowledge, peer relationships, teacher-child relationships 


\section{An investigation of the impact of young children's self-knowledge of trustworthiness on school adjustment: A test of the Realistic Self-Knowledge and Positive Illusion models}

Trustworthiness represents an individual's propensity to fulfil promises and maintain confidentiality (Rotenberg, Michalik, Eisenberg \& Betts, 2008). Trustworthiness is an important characteristic in the formation and maintenance of interpersonal relationships (Barefoot, Maynard, Beckham, Brummett \& Siegler, 1998; Fletcher, Simpson, Thomas \& Giles, 1999; Rotter, 1980) and, as such, is regarded as a highly valued personality trait (Cottrell, Neuberg \& Li, 2007). Further, researchers have found that trustworthiness is associated with psychosocial adjustment in children, including school adjustment (Betts \& Rotenberg, 2007a), number of friendships (Rotenberg et al., 2004), and preference by classmates as work partners (Wilson \& Carroll, 1991). However, there is a scarcity of research examining: (a) children's self-knowledge of trustworthiness, and (b) whether selfknowledge of trustworthiness is associated with psychosocial adjustment. The current study aimed to address these issues. Specifically, the study was designed to examine whether young children's (5- to 8-year-olds) self-knowledge of trustworthiness, using peer and teacher reports of trustworthiness as a reference, was associated with their school adjustment. Two models of self-knowledge were examined in the study: the Positive Illusion Model (Taylor \& Brown, 1988, 1994) and the Realistic Self-Knowledge Model (Colvin \& Block, 1994; Colvin, Block \& Funder, 1995).

The Positive Illusion Model, outlined by Taylor and Brown (1988), proposes that adjustment (i.e., being happy and contented) varies as a function of the extent to which individuals hold optimistic views about their own behaviour. According to these formulations, the more that individuals hold positive views of themselves, regardless of external criteria (e.g., observations, others' reports), then the better their adjustment. The term 'external criteria' is used to reflect the judgements made by others that can be used to 
assess the extent to which an individual's self-knowledge is warranted (Robins \& Beer, 2001). In support of this model, Taylor et al. (2003) reported that adults' self-enhancement is linearly associated with positive mental health and that greater self-enhancement results in greater benefits for mental health. Recently, Brookings and Seratelli (2006) reported that adults with positive illusions had greater life satisfaction and lower anxiety than those individuals without such positive illusions. Also, in the presence of others, adults tend to exaggerate positive illusions about themselves (Bromgard, Tafimow \& Bromgard, 2006).

There is some support for the Positive Illusion Model of psychosocial functioning for children. Hoza, Pelham, Dobbs, Owens and Pillow (2002) assessed the extent to which 7- to 12-year-old boys, with attention-deficit/hyperactivity disorder, had positive illusions of their scholastic competence. Positive illusions were assessed as the extent to which the boys' reports of their scholastic competence exceeded teachers' reports of the boys' scholastic competence. As support for the Positive Illusion Model, it was found that boys with positive illusions of their scholastic competence were less likely to develop negative self-perceptions than boys without such positive illusions. Further, individuals with attentiondeficit/hyperactivity disorder over-estimated their social competence more than the boys who formed a comparison group. Brendgen et al. (2004) assessed positive illusions in 8- to 13year-olds as the extent to which self-reports of social competence exceeded peers' reports of the children's social competence. In support of the Positive Illusion Model, it was found that children with positive illusions of their social competence were more positive about their friendships than children without such positive illusions. Finally, Kistner, David and Repper (2007) found that the extent to which third to fifth grade children had positive illusions about their peer acceptance (assessed by self versus peer reports), positively predicted changes in the children's self-worth and peer-reported peer acceptance six months later. 
The Realistic Self-Knowledge Model, outlined by Colvin and colleagues (Colvin \& Block, 1994; Colvin et al., 1995), proposes that mental health varies as a function of the extent to which individuals hold realistic views of themselves. According to these formulations, the more individuals hold views of themselves that are congruent as opposed to discrepant with external criteria (e.g., observations, others' reports), then the better their mental health. In adults, there is empirical evidence that over time unrealistic self-knowledge, in the form of self-enhancement, is associated with reduced self-esteem, ego involvement and wellbeing (Robins \& Beer, 2001). Further, Robins and Beer (2001) report that adults with unrealistic self-perceptions do not perform better academically and these adults are not more likely to graduate from university than individuals with realistic self-knowledge. Also, recent research suggests that adults with realistic self-knowledge of their self-esteem, using roommates as external criteria, have lower depression scores than adults who under- or over-estimate their self-esteem (Joiner, Kistner, Stellrecht \& Merrill, 2006). Moreover, these findings were replicated over a three-week period: realistic self-knowledge of self-esteem predicted lower levels of depression and anxiety whereas unrealistic self-knowledge of self-esteem predicted higher levels of depression and anxiety (Joiner et al., 2006).

In an examination of these issues with children, Pelton and colleagues (Pelton \& Forehand, 2001; Pelton et al., 2001) assessed realistic self-knowledge in adolescents by measuring whether their reports of the quality of the mother-adolescent relationship was congruent with their mother's reports. In support of the Realistic Self-Knowledge Model, it was found that adolescents with realistic perceptions experienced lower levels of withdrawal and fewer conduct problems, both concurrently and over a year, than adolescents with unrealistic self-knowledge. Pelton and Forehand (2001) interpreted these findings as demonstrating the principle that unrealistic perceptions create an environment of mistrust and frustration. 
In a further investigation, Cillessen and Bellmore (1999) assessed the extent to which fourth grade children showed realistic self-knowledge of their social competence by assessing the congruence between their self-ratings of likeability and peer-reports of liking. In support of the Realistic Self-Knowledge Model, it was found that children with realistic selfknowledge of their social competence experienced lower levels of loneliness than children with unrealistic self-knowledge. As an explanation of their findings, Cillessen and Bellmore (1999) proposed that children with unrealistic self-perceptions were prone to engage in inappropriate behaviour towards peers and thereby have negative peer interactions. Further, it was these interactions that resulted in the children experiencing loneliness. Finally, Gresham, Lane, MacMillian, Bocian and Ward (2000) compared third grade children's self-knowledge of their social self-concept and peers' reports of the children's self-concepts. In support of the Realistic Self-Knowledge Model, it was found that children with positive illusions were rated by their teachers as having lower social skills, more problem behaviours and lower academic competence.

Although the Positive Illusion and the Realist Self-Knowledge Model are opposing models of self-knowledge, it would be unwise to regard them as mutually exclusive. For example, although the congruence between self-knowledge and other-knowledge may be associated with psychosocial adjustment (as predicted by the Realistic Self-Knowledge Model), this relationship could be skewed such that a positive discrepancy between selfknowledge and other-knowledge is associated with psychosocial adjustment (as predicted by the Positive Illusion Model). These effects are represented by curvilinear and linear statistical relationships between self-knowledge and other-knowledge to psychosocial adjustment. Specifically, a positive linear relationship between self-knowledge and psychosocial adjustment would provide support for the Positive Illusion Model. Conversely, a curvilinear relationship where individuals with more accurate self-knowledge have higher psychosocial 
adjustment whereas individuals with less accurate self-knowledge would lower psychosocial adjustment would provide support for the Realistic Self-Knowledge Model.

The current research was designed to examine whether the relationship between young children's self-knowledge of trustworthiness, using others' knowledge as external criteria, would be associated with school adjustment. Consequently, two conceptualisations are crucial to the investigation: trustworthiness and school adjustment. Trustworthiness was conceptualised using the framework developed by Rotenberg and colleagues' (Rotenberg, Fox \& Boulton, 2005; Rotenberg et al., 2004). The framework includes two bases of trustworthiness: promise-keeping (reliability) and secret-keeping (emotional). According to the framework, individuals demonstrate these bases of trustworthiness towards targets who vary in specificity and familiarity. Specifically, the children's self-knowledge of their promise-keeping and secret-keeping (reliability and emotional trustworthiness, respectively) as compared to peers' and teachers' reports of these behaviours was examined in the present research. Although children as young as three can conceptualise trust (Harris, 2007), promise-keeping and secret-keeping were chosen as indicators of trustworthiness because these behaviours are observable and do not necessitate children inferring the target child's intentions. This is particularly desirable when assessing trustworthiness in 5- to 8-year-olds because children's ability to infer a target individual's intentions are emerging during this developmental period (Porath, 2003). Researchers have found that peer-reported trustworthiness is modestly stable across a year span in 5- to 7-year-olds (Betts \& Rotenberg, 2007a), across an 8-month span for 9- to 11-year-olds, and across a year-span in 11- to 14year-olds (Rotenberg et al., 2004).

School adjustment is a facet of psychosocial adjustment that has been conceptualised as the degree to which children are interested, engaged, comfortable and successful in the school environment (Ladd, 1996; Ladd, Buhs \& Troop, 2002). This domain has been assessed by 
children's self-reports of their disposition towards school (e.g., school-liking) and teacher reports of the children's behaviour and engagement in the classroom (e.g., on-task classroom involvement, Ireson \& Hallam, 2005; Rimm-Kaufman, Pianta, Cox \& Bradley, 2003; Stipek \& Byler, 2001; Valeski \& Stipek, 2001). School adjustment was assessed accordingly in the current investigation.

Previous research has identified a relationship between children's trustworthiness and their school adjustment (Betts \& Rotenberg, 2007a; Imber, 1973; Wentzel, 1991; Wilson \& Caroll, 1991). Two mechanisms have been proposed to account for this relationship: (1) trustworthiness may facilitate companionship between peers which may foster school adjustment and (2) trustworthiness may facilitate the development of intimacy between peers promoting school adjustment (Betts \& Rotenberg, 2007a). Although there is evidence that trustworthiness is important for children's school adjustment it remains unclear whether children's self-knowledge of trustworthiness is important for their school adjustment. Overview of the Current Study and Hypotheses

In the study, children from school years 1 and 2 (5- to 7-year-olds) in the United Kingdom were tested twice in one-year. Children's trustworthiness was assessed using: (a) self-report (secret-keeping and promise-keeping) at Time 1 and Time 2, (b) peers' reports at Time 1 and Time 2, and (c) teacher reports at Time 2. The latter two measures served as external criteria. Further, school adjustment was assessed by: (a) children's ratings of school-liking and (b) the Short-Form Teacher Rating Scale of School Adjustment. The congruence between children's self-knowledge of their trustworthiness and either peers' or teachers' knowledge of the children's trustworthiness was examined. The Positive Illusion Model predicts that a positive discrepancy between children's self-knowledge and external criteria (with the former exceeding the later) would be associated with school adjustment, both concurrently and longitudinally. The Realistic Self-Knowledge Model predicts that the size of the difference 
between children's self-knowledge and external criteria, whether positive or negative, would be associated with school adjustment and that children with larger differences would be less well adjusted. The analyses directly tested the extent to which each model accounted for school adjustment. Further, through using teachers to provide ratings of the children's trustworthiness and school adjustment, the present research also addresses the issue that if a child holds unrealistic self-perceptions for one measure then they may do so for the other measure.

\section{Method}

\section{Participants}

At Time 1 (November to January), 187 (94 male and 93 female) children in school years 1 and 2 participated from the 208 children approached, yielding a $89.90 \%$ response rate. The sample was reduced because parental permission was withheld $(n=14)$ and because some children declined to participate $(n=5)$. The mean age of the sample was 6 years and 2 months ( $S D=8$ months). The children were from nine classrooms across four schools that served a range of socio-economic areas. Three schools had catchment areas above the national average for professional employment and below the national average for unemployment, whilst one school's catchment area was below the national average for professional employment and above the national average for unemployment (Office for National Statistics, 2001). The sample was predominately white (97\%).

At Time 2, one year later (November to January), 173 (84 male and 89 female) children from the original sample completed the measures. The sample was reduced because children had either left the schools that they attended at Time $1(n=13)$, or were absent on the day of testing $(n=1)$. 


\section{Materials}

Self-knowledge of trustworthiness. A modified version of the peer-reported trustworthiness procedure outlined in Betts and Rotenberg (2007a) was used to assess children's self-reported trustworthiness. Specifically, participants reported the extent to which they thought that they kept their promises and the extent to which they thought that they kept their secrets using a 5point likert scale ranging from 1-- Never Ever to 5--Always. High scores represented higher self-reported trustworthiness. Self-reported promise-keeping and secret-keeping were moderately correlated at Time $1, r(185)=.40, p<.001$, and at Time $2, r(171)=.39, p<.001$, and as such these reports were combined to form a composite measure of self-reported trustworthiness at Time $1(M=7.54, S D=1.28)$ and at Time $2(M=7.08, S D=1.23)$.

\section{Other-Knowledge of Trustworthiness}

Peer. Betts and Rotenberg's (2007a) procedure was used to assess peer-reported promisekeeping and secret-keeping trustworthiness. Specifically, using a 5-point Likert scale (1-Never Ever to 5 -- Always), the children reported the extent to which they thought that each of their classmates kept their promises and secrets. To adjust for class size, an aggregate score was calculated for peer-reported promise-keeping trustworthiness and peer-reported secret-keeping trustworthiness. As peer-reported promise-keeping trustworthiness and peerreported secret-keeping trustworthiness were significantly correlated at Time $1, r(185)=.85$, $p<.001$, and at Time $2, r(171)=.82, p<.001$, these scores were combined to create a composite measure of peer-reported trustworthiness at Time $1(M=9.54, S D=1.27)$ and at Time $2(M=9.10, S D=1.57)$. The composite measure was stable across time, $r(171)=.72, p$ $<.001$.

Teacher. At Time 2, teachers completed the following item assessing general trustworthiness: "This child is trustworthy". The teachers responded to the item using a 7- 
point scale ranging from 1 -- Extremely Untrue to 7 -- Extremely True: high scores represented higher trustworthiness $(M=5.61, S D=1.50)$.

\section{School Adjustment}

Child-rated. This was assessed by the participants' completion of the School Liking and Avoidance Questionnaire (SLAQ). The SLAQ has been used extensively by Ladd and colleagues (Kochenderfer \& Ladd, 1996a, 1996b; Ladd, Kochenderfer \& Coleman, 1996; Ladd, Buhs \& Seid, 2000) and comprises two subscales. The nine-item school-liking subscale (e.g., 'Is school fun?') assesses children's school-liking and has a reported reliability of between 0.87 and 0.91 (Kochenderfer \& Ladd, 1996a, 1996b). The five-item school avoidance subscale (e.g., 'Do you wish you didn't have to go to school?') assesses children's tendency to avoid school and has a reported reliability between 0.76 and 0.81 (Kochenderfer \& Ladd, 1996b). The children responded to the items using a 3-point scale ranging from 1 -No to 3 -- Yes. The responses to the school-liking subscale and the school-avoidance subscale (reverse coded) were strongly associated at Time $1, r(181)=.69, p<.001$, and at Time 2, $r(165)=.77, p<.001$. Therefore, the subscales were combined to form a composite measure of child-rated school-liking that was reliable (Time $1 \alpha=.91$ and Time $2 \alpha=.94$ ) and moderately stable over time, $r(161)=.43, p<.001$.

Teacher-rated. The Short-Form Teacher Rating Scale of School Adjustment (Short-Form TRSSA) was used to assess teacher-rated school adjustment (Betts \& Rotenberg, 2007b). The 16-item Short-Form TRSSA comprises three subscales: on-task classroom involvement (e.g., “Follows teacher's directions"), maturity (e.g., "Is a mature child") and positive orientation (e.g., "Is cheerful at school"). The teachers responded to the items using a 3-point Likert scale ranging from 0 -- Doesn't Apply to 2 -- Certainly Applies. The Short-Form TRSSA has demonstrated acceptable internal consistency and validity (Betts \& Rotenberg, 2007b). 


\section{Procedure}

The SLAQ was read out loud to participants in small groups of 5 to 6 same-sex peers. The children were encouraged to provide their answers independently and honestly. The peerreported and self-reported trustworthiness measures were read individually to children, in an area away from the classroom. Prior to reporting trustworthiness, participants were given definitions of a promise and a secret and then asked to give their own definitions and examples (see Betts \& Rotenberg, 2007a).

After the children completed the measures, the class teachers completed the Short-Form TRSSA and the trustworthiness rating (at Time 2).

Consent for the research was initially given by the head teachers and then parents/guardians were sent letters describing the research which they were asked to return if they did not want their child/children to participate $(n=14)$. Additionally, the children were asked to give their consent; five children declined to participate

\section{Results}

\section{Self-Knowledge of Trustworthiness Using Peers as an External Criteria}

A self-knowledge of trustworthiness score, using peers as an external criteria, was calculated for each participant by subtracting the peer-reported trustworthiness score from each child's self-reported trustworthiness score at Time 1 and Time 2. Higher self-knowledge scores indicated that the child held inflated self-perceptions and was more positive about their own trustworthiness compared to their peers. The concurrent and longitudinal relationships between self-knowledge and school adjustment were initially examined through a series of correlations (Table 1). At Time 1 and at Time 2, there were significant negative concurrent relationships between self-knowledge of trustworthiness and teacher-rated school adjustment. Specifically, children with inflated self-perceptions of trustworthiness had lower scores on 
on-task classroom involvement, maturity and positive orientation whereas children with less inflated self-perceptions had higher scores on these measures.

Insert Table 1 here

A series of regressions that tested for both quadratic curvilinear relationships and linear relationships were used as a method of investigating the two models of self-knowledge and to examine the longitudinal relationships between self-knowledge of trustworthiness and school adjustment $^{1}$. Specifically, significant quadratic relationships would provide evidence in support of the Realistic Self-Knowledge Model because children could under- or overestimate their trustworthiness. Conversely, significant positive linear relationships would provide evidence in support of the Positive Illusion Model because if children had positive illusions (inflated self-perceptions) about their trustworthiness, the higher these illusions then the higher the children's school adjustment. For these analyses, the predictor variable was self-knowledge of trustworthiness at Time 1 and the outcome variables was the change in each measure of school adjustment between Time 1 and Time 2, following the procedure outlined by Cohen, Cohen, West and Aiken (2003). For the purpose of the analysis selfknowledge scores close to zero indicated realistic self-knowledge of trustworthiness whilst positive scores indicated positive illusions.

There was evidence of significant quadratic and linear relationships between selfknowledge at Time 1 and changes in school adjustment (Table 2). Specifically, a significant quadratic relationship was found between self-knowledge at Time 1 and change in on-task classroom involvement: smaller discrepancies between self-reported trustworthiness and peer-reported trustworthiness at Time 1 predicted increases in on-task classroom involvement and larger discrepancies predicted decreases in on-task classroom involvement over time (see 
Figure 1). There was also evidence of a negative linear relationship between self-knowledge and on-task classroom involvement: more inflated self-perceptions predicted decreases in ontask involvement over time. There were no other significant linear relationships.

Insert Figure 1 and Table 2 here

There was evidence of a quadratic relationship between self-knowledge and changes in maturity (Figure 2), positive orientation (Figure 3) and child-rated school-liking (Figure 4). Smaller discrepancies between self-reported trustworthiness and peer-reported trustworthiness at Time 1 predicted increases in maturity, positive orientation and child-rated school-liking whereas larger discrepancies at Time 1 predicted decreases in maturity, positive orientation and child-rated school-liking at Time 2. The quadratic relationships occurred because very inflated or very deflated self-perceptions of trustworthiness were predictive of decreases in school adjustment whereas more accurate self-knowledge was predictive of increases in school adjustment. These longitudinal quadratic relationships provide support for the Realistic Self-Knowledge Model because accurate self-knowledge was predicative of increases in school adjustment and less realistic self-knowledge was predictive of decreases in school adjustment over time.

Insert Figure 2, 3 and 4 here

To further examine the quadratic relationships, children were grouped according to their self-knowledge scores and ANOVAs performed to compare these groups for changes in ontask classroom involvement, maturity, positive orientation and school-liking (see Table 3 for means and standard deviations). Three groups were created according to the children's self- 
knowledge scores: (1) extreme low scores $(<-3.00)$, (2) midrange scores (>-2.99 and <2.99), and (3) extreme high scores (> 3.00). As expected, there were differences in children's selfknowledge scores and changes in on-task classroom involvement, $F(2,166)=12.60, p<.001$, $\eta^{2}=.132 ;$ maturity, $F(2,139)=6.14, p<.01, \eta^{2}=.081 ;$ and positive orientation, $F(2,164)=$ $10.87, p<.001, \eta^{2}=.117$. Planned comparisons revealed significant differences between the extreme low and the midrange children and between the extreme high and the midrange children's on-task classroom involvement, maturity and positive orientation $(p<.05)$. The was a marginally significant difference in children's self-knowledge scores and changes in school-liking, $F(2,160)=2.38, p=.096, \eta^{2}=.029$. Planned comparisons revealed a marginally significant difference in the changes in school-liking for the midrange and extreme high children $(p=.07)$.

Insert Table 3 here

\section{Self-Knowledge of Trustworthiness Using Teacher Reports as the External Criteria}

Self-knowledge of trustworthiness was also examined using teachers as the external criteria. To reflect the different response format of the self-reported and teacher-reported trustworthiness measures, standard scores were calculated for each measure. The standard score, calculated as z scores, for each individual child for teacher-reported trustworthiness was subtracted from the standard score of his/her self-reported trustworthiness at Time 2. High scores on this measure indicated inflated self-perceptions of trustworthiness.

Correlations were used to examine the concurrent relationships between self-knowledge and school adjustment. Self-knowledge was negatively associated with teacher-rated school adjustment: on-task classroom involvement, $r(170)=-.44, p<.001 ;$ maturity, $r(146)=-.40, p$ 
$<.001$; and positive orientation, $r(170)=-.37, p<.001$. Children with more inflated selfperceptions had lower on-task classroom involvement, maturity and positive orientation whereas children with less inflated self-perceptions had higher on-task classroom involvement, maturity and positive orientation. There was no such concurrent relationship between self-knowledge and school-liking, $r(146)=-.05, p>.05$.

Quadratic and linear regressions were used to further examine the relationship between self-knowledge of trustworthiness, using teachers as an external criteria, and school adjustment (Table 4). Significant linear and quadratic relationships were evident between self-knowledge, on-task classroom involvement (Figure 5), maturity (Figure 6) and positive orientation (Figure 7). Regarding the linear relationships, inflated self-perceptions (i.e., positive illusions) were predictive of lower teacher-rated school adjustment and deflated selfperceptions were predictive of higher teacher-rated school adjustment. There was no such linear relationship between self-knowledge and school-liking.

Insert Table 4 and Figure, 5, 6 and 7 here

The quadratic relationships revealed that children with more accurate self-perceptions had higher on-task classroom involvement, maturity, and positive orientation whereas those children with inflated or deflated self-perceptions had lower on-task classroom involvement, maturity and positive orientation. Across all three analyses, the quadratic relationship was asymmetric with those children with inflated self-perceptions having lower school adjustment than those children with extremely deflated self-perceptions. There was no such quadratic relationship between self-knowledge and school-liking.

To further examine these quadratic relationships, children were grouped according to their scores and ANOVA used to compare differences in the children's teacher-rated school 
adjustment according to their self-knowledge (see Table 5 for means and standard deviations). As the curvilinear relationship was asymmetric three groups were created according to the children's self-knowledge scores: (1) extreme low scores $(<-2.00),(2)$ midrange scores $(>1.99$ and $<2.00)$, and (3) extreme high scores $(>2.00)$. As expected, there were differences in children's self-knowledge scores and changes in on-task classroom involvement, $F(2,151)=10.05, p<.001, \eta^{2}=.117$; maturity, $F(2,128)=5.97, p<.01, \eta^{2}=$ .085 , and positive orientation, $F(2,151)=6.44, p<.01, \eta^{2}=.079$. Planned comparisons revealed significant differences between the extreme high and midrange children's on-task classroom involvement, positive orientation and maturity scores $(p<.05)$. Additionally, planned comparisons revealed marginally significant differences between the extreme low and midrange children's maturity $(p=.098)$ and positive orientation scores $(p=.083)$.

Insert Table 5 here

\section{Discussion}

The present study aimed to examine whether young children's self-knowledge of their trustworthiness conformed more closely to the Positive Illusion Model (Taylor \& Brown, 1988, 1994) or to the Realistic Self-Knowledge Model (Colvin \& Block, 1994; Colvin et al., 1995). These models were examined with regard to children's school adjustment as an indicator of psychosocial functioning. Using peers and teachers as external criteria, the present study provides support for the Realistic Self-Knowledge Model, rather than the Positive Illusion Model, as an explanation of the relationship between young children's selfknowledge of trustworthiness and their school adjustment. Further, these results were evident using two external criteria which suggests that the effect may be relatively robust whilst 
overcoming the problems associated with common method variance (see Lindell \& Whitney, 2001). In particular, young children's realistic self-knowledge was concurrently associated with, and longitudinally predicted changes in, school adjustment. Further, when the positive Illusion Model was examined, contrary to expectation, there were negative relationships between positive self-knowledge of trustworthiness and school adjustment. Together these findings add to the growing literature that argues that realistic self-knowledge is crucial for children's psychosocial functioning (Cillessen \& Bellmore, 1999; Gresham et al., 2000; Pelton \& Forehand, 2001; Pelton et al., 2001).

There are two potential explanations that account for the present findings that realistic self-knowledge rather than positive illusions are important for school adjustment. First, the results may have emerged because of the importance of trustworthiness for the development of social relationships with peers and teachers. Specifically, trustworthiness is crucial for the development and maintenance of positive relationships with others (Rotenberg et al., 2004; Rotter, 1980). Therefore, it may be that, for children, being aware of how you are perceived by others in terms of trustworthiness helps the formation of relationships with peers and teachers and that developing supportive relationships with these individuals may foster school adjustment. Further, those children with accurate self-knowledge may also engage in behaviours that are desired by peers and teachers. In support of this argument the role of peer relationships and teacher relationships for an individual's school adjustment has been widely recognised (Berndt \& Keefe, 1996; Ladd, 1990; Wentzel, Barry \& Caldwell, 2004).

The second explanation resides in the children's interpersonal perception skills. According to Cillessen and Bellmore (2002) children's self-perception ability develops from interactions with others and social cognitions formed during interactions. With regard to children's selfperception ability it may be that some children are unable to accurately self-monitor their behaviour because they do not engage in social relationships where this skill can be fostered 
(Cillessen \& Bellmore, 2002). Therefore, those children with unrealistic self-knowledge of their trustworthiness could develop such self-knowledge because they do not engage in appropriate social relationships where this behaviour can be addressed. In support of this argument researchers have reported that children tend to develop self-perceptions based on their interactions with others (Cole, 1991). Alternatively, the children's social cognitions may be instrumental in their development of self-knowledge and in the relationships that they develop with their peers (Cillessen \& Bellmore, 2002). Consequently, children with an unrealistic self-knowledge of their trustworthiness may experience poorer school adjustment because they are less self-aware and engage in less self-monitoring. Therefore, these children may engage in inappropriate behaviour which may adversely affect their school adjustment.

At a more general level, the present research also has implications for the development of children's self-knowledge. The results of the present study may reflect that young children are beginning to recognise that others evaluate the self and these evaluations may influence the child's sense of self (Harter, 1999). Further, during this time children are beginning to recognise attributes and personality traits (Harter, 1996). This emerging sense of others as evaluators may account for the modest stability in the children's self-knowledge of trustworthiness. Related to this emerging sense of others there is the possibility that children may experience attribution biases of another child regarding their trustworthiness similar to the biases for aggression (Dodge, 1980; Dodge \& Somberg, 1987) and the intentions of liked peers and disliked peers (Guerin, 1999). Therefore, future research could examine the potential attribution bias that may occur in the children's ratings of trustworthiness.

The findings of the present study also contribute to the growing literature that argues the importance of children's trustworthiness for their school adjustment (Betts \& Rotenberg 2007a; Imber, 1973; Rotenberg et al., 2004; Wentzel, 1991; Wilson \& Caroll, 1991). Together these studies suggest that the role of trustworthiness cannot be overlooked as part of 
children's school adjustment. Further, as children with less realistic self-knowledge of their trustworthiness are more likely to experience difficulties adjusting to school than those children with realistic self-knowledge of their trustworthiness, there are a number of implications for both teachers and their pupils. From the perspective of the teacher, developing an awareness that some children have unrealistic self-perceptions could help teachers to facilitate the children's school adjustment. Specifically, if a teacher was to become aware that a child has unrealistic self-knowledge of trustworthiness they could try to build in to the curriculum the importance of self-awareness. Future research also examining the antecedents of self-knowledge could also help in the development of curriculum for teachers.

With regard to the children, the research suggests that those children who are less aware of how they are perceived by their peers and teachers in terms of their trustworthiness are more 'at risk' of developing poorer school adjustment. Therefore, interventions could be developed to try to foster self-awareness within these individuals of their trustworthiness. Successfully increasing children's self-awareness of their trustworthy behaviour would ultimately promote their school adjustment. Moreover, Harrist and Bradley (2003) report a successful intervention to increase inclusivity within young children's classrooms and the ultimate effect of promoting inclusivity was to increase children's favourability. Therefore, similar interventions could be developed with the overall aim of increasing children's selfknowledge of trustworthiness.

The present research also has implications for assessing trustworthiness in future research. Previous research has typically examined an individual's trustworthiness from the perspective of external criteria such as peers or teachers and then used these other reports of trustworthiness in subsequent analysis (e.g., Betts \& Rotenberg, 2007a). However, adopting such an approach does not allow conclusions to be drawn concerning whether it is how the 
children are perceived by others or their self-knowledge of trustworthiness that is important for adjustment. Therefore, researchers could further examine children's self-knowledge of trustworthiness. One mechanism for this investigation is examining children's metaperceptions of their trustworthiness. Examining metaperceptions would allow inferences to be made about the difference between self-knowledge and external criteria at an individual level. Specifically, investigation of metaperceptions of trustworthiness would allow conclusions to be drawn about the accuracy with which an individual child perceived their trustworthiness according to each external criteria report, rather than using the global report of the external criteria as in the present study. This would involve each child reporting the extent to which they think that each of their peers thinks that the child is trustworthy. Examination of this phenomenon would allow researchers to draw conclusions about how each individual child thinks that they are regarded by each individual external criteria. Further, this would allow investigation into a child's accuracy in their self-knowledge at the level of the individual.

Future research could also develop the measures used to assess trustworthiness. Specifically, in the present research teacher-reported trustworthiness was assessed using a single item. Although the use of a single item measure could be limiting, the measurement of teacher-reported trustworthiness needs to reflect that teachers do not have access to the same array of trustworthy behaviours that other informants such as peers do. For example, because of the private nature of secret-keeping teachers may miss some instances of trustworthy behaviour in these contexts. Further, from the modest stability and modest effect sizes reported, it is possible that other factors may be influential in the development of children's self-knowledge of trustworthiness and children's adjustment to school. Therefore, future research could also examine other variables that may be influential to school adjustment such 
as additional measures of the children's behavioural functioning (Perry \& Weinstein, 1998) or socio-economic status (Entwisle, Alexander \& Olson, 2005).

In summary, the present research has contributed to the growing literature examining the effects of self-knowledge. However, the present study represents a unique contribution because it is the first such study to examine the role of young children's self-knowledge of their trustworthiness for school adjustment. The findings suggest that, consistent with Colvin and colleagues' theory (Colvin \& Block, 1994; Colvin et al., 1995), realistic self-perceptions are more important for adjustment than positive illusory bias particularly with regard to young children's self-knowledge of trustworthiness and their school adjustment. The research also adds further support for the importance of trustworthiness for children's school adjustment (e.g., Betts \& Rotenberg, 2007a; Imber, 1973; Rotenberg et al., 2004; Wilson \& Carroll, 1991) and the research that has highlighted the importance of children's peer relationships (e.g., Ladd, Birch \& Buhs, 1999) and the teacher-child relationship (e.g., Birch \& Ladd, 1997, 1998) for their early school adjustment. 


\section{References}

Barefoot, J. C., Maynard, K. E., Beckham, J. C., Brummett, B. H. H. K., \& Siegler, I. C. (1998). Trust, health and longevity. Journal of Behavioral Medicine, 21, 517-526.

Berndt, T., \& Keefe, K. (1996). Friends' influence on school adjustment: A motivational analysis. In J. Juvonen \& K. R. Wentzel (Eds.), Social motivation: Understanding children's school adjustment (pp. 248-278). Cambridge: Cambridge University Press.

Betts, L. R., \& Rotenberg, K. J. (2007a). Trustworthiness, friendship and self-control: Factors that contribute to young children's school adjustment. Infant and Child Development, 16, 491-508.

Betts, L. R., \& Rotenberg, K. J. (2007b). The Development of a Short-Form of the Teaching Rating Scale of School Adjustment. Journal of Psychoeducational Assessment, 25, 150164.

Birch, S. H., \& Ladd, G. W. (1997). The teacher-child relationship and children's early school adjustment. Journal of School Psychology, 35, 61-79.

Birch, S. H., \& Ladd, G. W. (1998). Children's interpersonal behaviors and the teacher child relationship. Developmental Psychology, 34, 934-946.

Brendgen, M., Vitaro, F., Turgeon, L., Poulin, F., \& Wanner, B. (2004). Is there a dark side of positive illusions? Overestimation of social competence and subsequent adjustment in aggressive and nonaggressive children. Journal of Abnormal Child Psychology, 32, 305320.

Bromgard, G. D., Trafimow, D., \& Bromgard, I. K. (2006). Valence of self-cognitions: The positivity of individual self-statements. The Journal of Social Psychology, 146, 85-94.

Brookings, J. B., \& Serratelli, A. (2006). Positive illusions: Positively correlated with subjective well-being, negatively correlated with a measure of personal growth. Psychological Reports, 98, 407-413. 
Cillessen, A. H. N., \& Bellmore, A. D. (1999). Accuracy of social self perceptions and peer competence in middle childhood. Merrill-Palmer Quarterly, 45, 650-676.

Cillessen, A. H. N., \& Bellmore, A. D. (2002). Social skills and interpersonal perception in early and middle childhood. In P. K. Smith \& C. H. Hart (Eds). Blackwell handbook of childhood social development. (pp. 355-374). Oxford: Blackwell publishers.

Cole, D. A. (1991). Change in self-perceived competence as a function of peer and teacher evaluation. Developmental Psychology, 27, 682-688.

Cohen, J., Cohen, P., West, S. G., \& Aiken, L. S. (2003). Applied multiple regression/correlation analysis for the behavioral sciences $\left(3^{\text {rd }}\right.$ ed). Mahawah, New Jersey, Lawrence Erlbaum.

Colvin, C. R., \& Block, J. (1994). Do positive illusions foster mental health? An examination of the Taylor and Brown formulation. Psychological Bulletin, 116, 3-20.

Colvin, C. R., Block, J., \& Funder, D. C. (1995). Overly positive self-evaluations and personality: Negative implications for mental health. Journal of Personality and Social Psychology, 68, 1152-1162.

Cottrell, C. A., Neuberg, S. L., \& Li, N. P. (2007). What do people desire in others? A sociofunctional perspective on the importance of different valued characteristics. Journal of Personality and Social Psychology, 92, 208-231.

Dodge, K. A. (1980). Social cognition and children's aggressive behavior. Child Development, 51, 162-170.

Dodge, K. A., \& Somberg, D. R. (1987). Hostile attributional biases among aggressive boys are exacerbated under conditions of threats to the self. Child Development. 58, 213-224.

Entwisle, D. R., Alexander, K. L., \& Olson, L. S. (2005). First grade and educational attainment by age 22: A new story. American Journal of Sociology, 110, 1458-1502. 
Fletcher, G. J. O., Simpson, J. A., Thomas, G., \& Giles, L. (1999). Ideals in intimate relationships. Journal of Personality and Social Psychology, 76, 72-89.

Gresham, F. M., Lane, K. L., MacMillan, D. L., Bocian, K. M., \& Ward, S. L. (2000). Effects of positive and negative illusory biases: Comparisons across social and academic selfconcept domains. Journal of School Psychology, 38, 151-175.

Guerin, B. (1999). Children's intergroup attribution bias for liked and disliked peers. Journal of Social Psychology, 139, 583-589.

Harris, P. L. (2007). Trust. Developmental Science, 10, 135-138.

Harrist, A. W., \& Bradley, K. D. (2003). "You can’t say you can’t play”: Intervening in the process of social exclusion in kindergarten classroom. Early Childhood Research Quarterly, 18, 185-205.

Harter, S. (1996). Developmental changes in self-understanding across the 5 to 7 year shift. In A. J. Sameroff \& M. M. Haith (Eds.), The five to seven shift: The age of reason and responsibility (pp. 207-236). Chicago: The Universiry of Chicago Press.

Harter, S. (1999). The construction of the self: A developmental perspective. New York: The Guilford Press.

Hoza, B., Pelham, W. E., Dobbs, J., Owens, J. S., \& Pillow, D. R. (2002). Do boys with attention-deficit/hyperactivity disorder have positive illusory self-concepts? Journal of Abnormal Psychology, 111, 268-278.

Imber, S. (1973). Relationship of trust to academic performance. Journal of Personality and Social Psychology, 28, 145-150.

Ireson, J., \& Hallam, S. (2005). Pupils' liking for school: Ability grouping, self-concept and perceptions of teaching. British Journal of Educational Psychology, 75, 297-311. 
Joiner, T. E., Kistner, J. A., Stellrecht, N. E., \& Merrill, K. A. (2006). On seeing clearly and thriving interpersonal perspicacity as adaptive (non depressive) realism (or where three theories meet). Journal of Social and Clinical Psychology, 25, 542-564.

Kistner, J., David, C., \& Repper, K. (2007). Self-enhancement of peer acceptance: Implications for children's self-worth and interpersonal functioning. Social Development, 16, 24-44.

Kochenderfer, B. J., \& Ladd, G. W. (1996a). Peer victimization: Cause or consequence of school maladjustment? Child Development, 67, 1305-1317.

Kochenderfer, B. J., \& Ladd, G. W. (1996b). Peer victimization: Manifestations and relations to school adjustment in kindergarten. Journal of School Psychology, 34, 267-283.

Ladd, G. W. (1990). Having friends, keeping friends, making friends, and being liked by peers in the classroom: Predictors of children's early school adjustment? Child Development, 61, 1081-1100.

Ladd, G. W. (1996). Shifting ecologies during the 5 to 7 year period: Predicting children's school adjustment during the transition to grade. In A. J. Sameroff \& M. M. Haith (Eds). The age of reason and responsibility. (pp. 363-386) Chicago: The University of Chicago press.

Ladd, G. W., Birch, S. H., \& Buhs, E. S. (1999). Children's social and scholastic lives in kindergarten: related spheres of influence? Child Development, 70, 1373-1400.

Ladd, G. W., Buhs, E. S. \& Seid, M. (2000). Children's initial sentiments about kindergarten: Is school liking an antecedent of early classroom participation and achievement? MerrillPalmer Quarterly, 46, 255-279.

Ladd, G. W., Buhs, E. S., \& Troop, W. (2002). Children's interpersonal skills and relationships in school settings: Adaptive significance and implications for school based 
prevention and programs. In P. K. Smith \& C. Hart (Eds.) Blackwell handbook of childhood social development. (pp. 394-415). Oxford: Blackwell publishers.

Ladd, G. W., Kochenderfer, B. J., \& Coleman, C. C. (1996). Friendship quality as a predictor of young children's early school adjustment. Child Development, 67, 1103-1118.

Lee, S-Y., Song, X-Y., \& Poon, W-Y. (2004). Comparison of approaches in estimating interaction and quadratic effects of latent variables. Multivariate Behavioral Research, 39, 37-67.

Lindell, M. K., \& Whitney, D. J. (2001). Accounting for common method variance in crosssectional research designs. Journal of Applied Psychology, 86, 114-121.

Office for National Statistics (2001). 2001 Census: Standard Area Statistics (England and Wales) accessed via http://census.ac.uk/casweb/ retrieved 8/05/08.

Pelton, J., \& Forehand, R. (2001). Discrepancy between mother and child perceptions of their relationship: I. Consequences for adolescents considered within the context of parental divorce. Journal of Family Violence, 16, 1-15.

Pelton, J., Steele, R. G., Chance, M. W., Forehand, R., \& The Family Health project Research Group. (2001). Discrepancy between mother and child perceptions of their relationship: II. Consequences for children considered within the context of maternal physical illness. Journal of Family Violence, 16, 17-35.

Perry, K. E., \& Weinstein, R. S. (1998). The social context of early schooling and children's school adjustment. Educational Psychologist, 33, 177-194.

Porath, M. (2003). Social understanding in the first years of school. Early Childhood Research Quarterly, 18, 468-484.

Rimm-Kaufman, S. E., Pianta, R. C., Cox, M. J., \& Bradley, R. H. (2003). Teacher-rated involvement and children's social and academic outcomes in kindergarten. Early Education and Development, 14, 179-198. 
Robins, R. W., \& Beer, J. S. (2001). Positive illusions about the self: Short-term benefits and long-term costs. Journal of Personality and Social Psychology, 80, 340-352.

Rotenberg, K. J., Fox, C. L., \& Boulton, M. J. (2005, April). Conceptual model for the investigation of trustworthiness in children. In K. J. Rotenberg (Chair), Trustworthiness in children: Conceptual framework, school adjustment, and testimony as a witness. Symposium conducted at the Society of Research in Child Development Biennial meeting, Atlanta, Georgia.

Rotenberg, K. J., McDougall, P., Boulton, M. J., Vaillancourt, T., Fox, C., \& Hymel, S. (2004). Cross-sectional and longitudinal relations among peer-reported trustworthiness, social relationships, and psychological adjustment in children and early adolescents from the United Kingdom and Canada. Journal of Experimental Child Psychology, 88, 46-67.

Rotenberg, K. J., Michalik, N., Eisenberg, N., \& Betts, L. R. (2008). The relations among young children's peer-reported trustworthiness, inhibitory control and preschool adjustment. Early Childhood Research Quarterly, 23, 288-298.

Rotter, J. B. (1980). Interpersonal trust, trustworthiness and gullibility. American Psychologist, 35, 1-7.

Stipek, D., \& Byler, P. (2001). Academic achievement and social behaviors associated with age of entry into kindergarten. Journal of Applied Developmental Psychology, 22, 175189.

Taylor, S. E., \& Brown, J. D. (1988). Illusion and well-being: A social psychological perspective on mental health. Psychological Bulletin, 103, 193-210.

Taylor, S. E., \& Brown, J. D. (1994). Positive illusions and well-being revisited: Separating fact from fiction. Psychological Bulletin, 116, 21-27. 
Taylor, S. E., Lerner, J. S., Sherman, D. K., Sage, R., \& McDowell, N. K. (2003). Portrait of the self-enhancer: Well adjusted and well liked or maladjusted and friendless? Journal of Personality and Social Psychology, 84, 165-167.

Valeski, T. N., \& Stipek, D. J. (2001). Young children's feelings about school. Child Development, 72, 1198-1213.

Wentzel, K. R. (1991). Relationships between social competence and academic achievement in early adolescence. Child Development, 62, 1066-1078.

Wentzel, K. R., Barry, C. M., \& Caldwell, K. A. (2004). Friendships in middle school: Influences on motivation and school adjustment. Developmental Psychology, 96, $195-$ 203.

Wilson, J. N., \& Carroll, J. L. (1991). Children's trustworthiness: judgements by teachers, parents and peers. In K. J. Rotenberg (Ed.) Children's interpersonal trust: sensitivity to lying, deception and promise violation. (pp. 100-117). New York: Springer-Verlag. 


\section{Footnote}

${ }^{1}$ Regression methods were used to test the expected quadratic relationships, in preference to Structural Equation Modeling, because of the potential difficulties in identifying model parameters with sample sizes less than 300 when non-linear models are examined (see Lee, Song \& Poon, 2004). 
Table 1:

Concurrent and Longitudinal Correlations between Self-Knowledge of Trustworthiness, Using Peers as an External Criteria, and School Adjustment.

\begin{tabular}{|c|c|c|c|c|c|c|c|c|c|c|c|}
\hline & \multirow[b]{2}{*}{$M$} & \multirow[b]{2}{*}{$S D$} & \multicolumn{4}{|c|}{ Time 1} & \multicolumn{5}{|c|}{ Time 2} \\
\hline & & & SL1 & OI1 & M1 & PO1 & SK2 & SL2 & OI2 & M2 & PO2 \\
\hline \multicolumn{12}{|l|}{ Time 1} \\
\hline Self-Knowledge & 2.00 & 1.72 & -.13 & $-.41^{* * * *}$ & $-.35^{* * *}$ & $-.23^{* *}$ & $.30^{* * * *}$ & -.08 & $-.40^{* * * *}$ & $-.20^{*}$ & $-.16^{*}$ \\
\hline School-liking (SL1) & 28.73 & 8.69 & & .14 & $.26^{* * *}$ & .08 & $-.18^{*}$ & $.43^{* * *}$ & .12 & .16 & .08 \\
\hline On-task classroom involvement (OI1) & 9.80 & 2.44 & & & $.56^{* * *}$ & $.59^{* * *}$ & $-.25^{* * *}$ & .12 & $.56^{* * *}$ & $.49^{* * *}$ & $.37^{* * *}$ \\
\hline Maturity (M1) & 5.76 & 2.61 & & & & $.46^{* * *}$ & $-.16^{*}$ & $.17^{*}$ & $.52^{* * *}$ & $.39^{* * *}$ & $.41^{* * *}$ \\
\hline Positive orientation (PO1) & 7.99 & 2.04 & & & & & -.12 & .05 & $.21^{* *}$ & $.31^{* * * *}$ & $.34^{* * * *}$ \\
\hline \multicolumn{12}{|l|}{ Time 2} \\
\hline Self-Knowledge (SK2) & 1.99 & 1.84 & & & & & & -.13 & $-.27^{* * * *}$ & $-.22^{* *}$ & $-.18^{*}$ \\
\hline School-liking (SL2) & 29.32 & 9.08 & & & & & & & $.18^{*}$ & $.22^{* *}$ & .07 \\
\hline On-task classroom involvement (OI2) & 9.78 & 2.57 & & & & & & & & $.55^{* * *}$ & $.57^{* * *}$ \\
\hline Maturity (M2) & 5.72 & 2.43 & & & & & & & & & $.62^{* * *}$ \\
\hline Positive orientation (PO2) & 8.17 & 2.20 & & & & & & & & & \\
\hline
\end{tabular}

Note: $d f$ between 144 and 185 due to missing data

$$
* * * p<.001, * * p<.01, * p<.05
$$


Table 2.

Summary of the Regression Analyses for Self-Knowledge of Trustworthiness, Using Peers as an External Criteria, at Time 1 and School Adjustment at Time 2

\begin{tabular}{|c|c|c|c|c|c|}
\hline Outcome variable at Time 2 & Type of relational effect & $R^{2}$ & $B$ & $S E$ & $\beta$ \\
\hline \multirow{3}{*}{$\begin{array}{l}\text { On-task classroom } \\
\text { involvement }\end{array}$} & Linear & .03 & -.11 & .04 & $-.20^{*}$ \\
\hline & & & & & \\
\hline & Quadratic & .11 & -.05 & .01 & $-.38^{* * *}$ \\
\hline \multirow[t]{2}{*}{ Maturity } & Linear & -.01 & -.03 & .05 & -.04 \\
\hline & Quadratic & .05 & -.04 & .01 & $-.33^{* *}$ \\
\hline \multirow[t]{2}{*}{ Positive orientation } & Linear & .01 & -.06 & .05 & -.10 \\
\hline & Quadratic & .08 & -.05 & .01 & $-.37^{* * *}$ \\
\hline \multirow[t]{2}{*}{ School-liking } & Linear & -.01 & -.01 & .05 & -.01 \\
\hline & Quadratic & .02 & -.03 & .01 & $-.21^{*}$ \\
\hline
\end{tabular}


Table 3.

Means and Standard Deviations for the Changes in School Adjustment According to

Children's Self-Knowledge Scores, Classified as Extreme Low, Midrange and Extreme High, Using Peers as External Criteria at Time 1.

\begin{tabular}{|c|c|c|c|c|c|c|}
\hline & \multicolumn{6}{|c|}{ Self-knowledge of trust } \\
\hline & \multicolumn{2}{|c|}{ Extreme low } & \multicolumn{2}{|c|}{ Midrange } & \multicolumn{2}{|c|}{ Extreme high } \\
\hline & $M$ & $S D$ & $M$ & $S D$ & $M$ & $S D$ \\
\hline On-task classroom involvement & $-1.13^{\mathrm{ac}}$ & 1.04 & $.22^{\mathrm{b}}$ & .78 & $-.54^{\mathrm{ac}}$ & 1.28 \\
\hline Maturity & $-1.58^{\mathrm{ac}}$ & 2.06 & $.15^{\mathrm{b}}$ & .90 & $-3.54^{\mathrm{ac}}$ & 1.07 \\
\hline Positive orientation & $-1.31^{\mathrm{ac}}$ & 1.30 & $.20^{\mathrm{b}}$ & .90 & $-.47^{\mathrm{ac}}$ & 1.00 \\
\hline School-liking & $-.68^{\mathrm{ac}}$ & .94 & $.10^{\mathrm{b}}$ & .97 & $-.23^{\mathrm{ac}}$ & 1.04 \\
\hline
\end{tabular}

Note: Within rows means with different subscripts are significantly different at $p<.05$, except for school liking where $p=.07$ 
Table 4.

Summary of the Regression Analyses for Self-Knowledge of Trustworthiness, Using Teachers as an External Criteria, at Time 2 and School Adjustment at Time 2

\begin{tabular}{|c|c|c|c|c|c|}
\hline Outcome variable at Time 2 & Type of relational effect & $R^{2}$ & $B$ & $S E$ & $\beta$ \\
\hline \multirow{3}{*}{$\begin{array}{l}\text { On-task classroom } \\
\text { involvement }\end{array}$} & Linear & .19 & -.79 & .13 & $-.44^{* * * * *}$ \\
\hline & & & & & \\
\hline & Quadratic & .25 & -.17 & .05 & $-.28^{* * *}$ \\
\hline \multirow[t]{2}{*}{ Maturity } & Linear & .17 & -.73 & .13 & $-.42^{* * *}$ \\
\hline & Quadratic & .19 & -.11 & .05 & $-.18^{*}$ \\
\hline \multirow[t]{2}{*}{ Positive orientation } & Linear & .14 & -.58 & .12 & $-.38^{* * *}$ \\
\hline & Quadratic & .16 & -.09 & .04 & $-.17^{*}$ \\
\hline \multirow[t]{2}{*}{ School-liking } & Linear & .01 & -.76 & .54 & -.12 \\
\hline & Quadratic & .01 & -.17 & .20 & -.07 \\
\hline
\end{tabular}


Table 5 .

Means and Standard Deviations for School Adjustment According to Children's SelfKnowledge scores, Classified as Extreme Low, Midrange and Extreme High, Using Teachers as External Criteria at Time 2.

\begin{tabular}{|c|c|c|c|c|c|c|}
\hline & \multicolumn{6}{|c|}{ Self-knowledge of trust } \\
\hline & \multicolumn{2}{|c|}{ Extreme low } & \multicolumn{2}{|c|}{ Midrange } & \multicolumn{2}{|c|}{ Extreme high } \\
\hline & $M$ & $S D$ & $M$ & $S D$ & $M$ & $S D$ \\
\hline On-task classroom involvement & 10.71 & 1.82 & 10.00 & 2.44 & 6.44 & 2.88 \\
\hline Maturity & 9.29 & 2.13 & 8.34 & 2.14 & 6.00 & 2.60 \\
\hline Positive orientation & 6.86 & 1.88 & 5.76 & 2.36 & 3.14 & 2.61 \\
\hline
\end{tabular}

Note: Within rows means with different subscripts are significantly different at $p<.05$, except for between the extreme low and midrange maturity where $p=.098$ and positive orientation where $p=.083$. 
Figure Caption

Figure 1. Longitudinal linear and quadratic relationships between self-knowledge of trustworthiness using peer reports as an external criteria at Time 1 and on-task classroom involvement at Time 2.

Figure 2. Longitudinal linear and quadratic relationships between self-knowledge of trustworthiness using peer reports as an external criteria at Time 1 and maturity at Time 2.

Figure 3. Longitudinal linear and quadratic relationships between self-knowledge of trustworthiness using peer reports as an external criteria at Time 1 and positive orientation at Time 2.

Figure 4. Longitudinal linear and quadratic relationships between self-knowledge of trustworthiness using peer reports as an external criteria at Time 1 and child-rated school-liking at Time 2.

Figure 5. Concurrent linear and quadratic relationships between self-knowledge of trustworthiness using teacher reports as an external criteria at Time 2 and on-task classroom involvement at Time 2 .

Figure 6. Concurrent linear and quadratic relationships between self-knowledge of trustworthiness using teacher reports as an external criteria at Time 2 and maturity at Time 2.

Figure 7. Concurrent linear and quadratic relationships between self-knowledge of trustworthiness using teacher reports as an external criteria at Time 2 and positive orientation at Time 2. 